\title{
BUSINESS LETTER ON AN OSTRACON
}

\author{
FRANCISCA A. J. HOOGENDIJK
}

This Greek ostracon belongs to the private collection in Leiden of Mr. A. Fatatri, and I am most grateful for his permission to publish it here. It was bought on the antiquities market, together with the demotic ostraca edited in the present volume, p. 151 and p. 160 . They were all said to come from Thebes. The text may be assigned to the second half of the second century A.D. on palaeographical grounds.

The overall appearance of the handwriting is reminiscent of that of the Florida ostraca of the middle of the second century (cf. pp. 3-5), especially O. Florida 15 (Plate 7), although some of the letter forms differ. As is suggested by the parallel, Roman influence on the script is possible. For the $\eta$ with curve to the left (line 5), see W. Schubart, Griechische Paläographie, Abb. 42. The v, drawn with its stem upwards, is of the "rising type"'; see J. P. Gumbert, P. L. Bat. 14, pp. 1-12.

The ostracon contains a business letter from Paulinus to Serenus, whom he addresses as his brother, and perhaps they actually were brothers. The contents are difficult to reconstruct, especially as the end of each line is lacking. It is certain, however, that Serenus had previously sent a letter to Paulinus, asking him to do something, and the present letter is Paulinus' reply in which he tells him that he has done his best to act accordingly. He reports now that he had succeeded in obtaining something in exchange for or instead of four artabas of a certain commodity. This may have been five artabas of the same commodity (see line 4 , note). The drift of lines 5-6 might just possibly be that Paulinus struck a good bargain and received the five artabas at the price of four. But here we are only guessing.

TExT

Plate V

Thebes

$11.3 \times 9 \mathrm{~cm}$.

II A.D.

Potsherd: thickness: $0.5-0.9 \mathrm{~cm}$; colour: reddish brown; on the front two dark brown bands which were part of the decoration of the original pot; the back is ribbed and not inscribed. The text is complete on three sides, but broken away at the right.

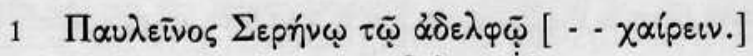

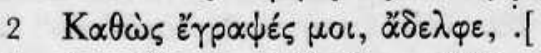

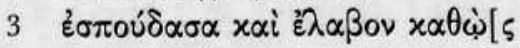

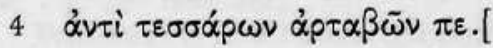

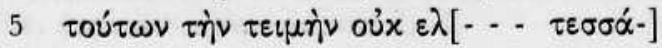


$6 \rho \omega \nu \alpha \dot{\rho} \tau \alpha \beta \tilde{\omega} \nu(\delta \rho \alpha \chi \mu.) \delta \pi 0 \lambda \varepsilon i \tau[$

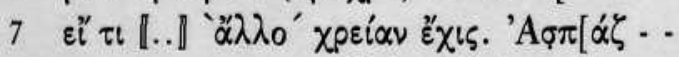

\section{Translation}

1 Paulinus to his brother Serenus, [ - - greetings.]

2 In conformity with what you have written to me, brother, [

3 I have done my best, and I have obtained, in conformity with [

4 for four artabas fi[ve (?)

5 the price thereof [I (?)] did not - - [

6 of four artabas 4 drachmas poleit [ - - . Let me know (?)]

7 if in any other way you have need. Greetings [to/from

I pray for your health.

\section{NOTES TO THE TEXT}

$\pi 0 \lambda \lambda \dot{\alpha} / \pi \lambda \varepsilon \tilde{\tau} \sigma \tau \alpha \chi \alpha i p \varepsilon t \nu$ or simply $\chi \alpha i p e t v$ may be supplied. This tells us nothing about the length of the lacuna, for something like xai xupí may also have stood there (cf. O. Lund. 12, 1-2).

2 Perhaps $\pi[\varepsilon p i \cdots$.

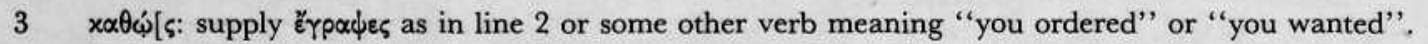

4 If $\pi \varepsilon$. [ belongs to the preceding sentence, $\pi \dot{\varepsilon} \psi[\tau \varepsilon$ of course suggests itself. If we should punctuate after $\alpha$ $\tau \alpha \beta \bar{\omega} \nu$, perhaps a form of $\pi \varepsilon \dot{\varepsilon} \mu \pi \omega$.

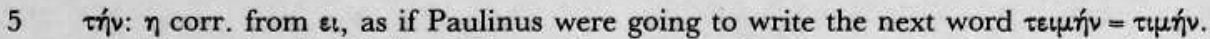

- oủx $\varepsilon \lambda$ [: maybe oủx $\varepsilon$ [ $\alpha$ ß ov. This could mean that Paulinus received something (the fi[ve artabas?]), but

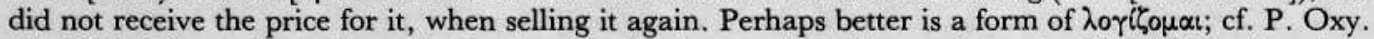

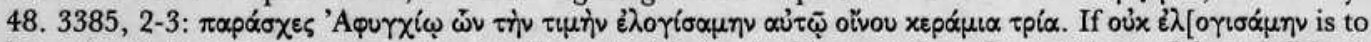
be restored, the sense may have been: "I received instead of four artabas, five artabas; of these I did not

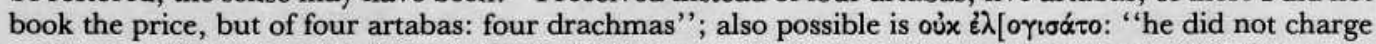
me (or you) the price of the five artabas but of four artabas: four drachmas." In this case the subject, the seller of the five artabas (?), will have been mentioned in one of the lacunas above.

6 Four artabas at four drachmas would concern something very cheap (see A. C. JoHNson, Roman Egypt to the Reign of Diocletian [1936], pp. 310-321).

- The numeral letter is written in such a way that one might think of 4000; but it rather seems that the delta is made with a right oblique which started at the upper left, as in P. Hamb. 1. 39 passim (Taf. $\mathrm{XI} / \mathrm{XII})$.

- $\quad \pi 0 \lambda \varepsilon เ \tau\left[\right.$ : maybe $\pi 0 \lambda \varepsilon i \tau\left[\alpha \iota\right.$ for $\pi \omega \lambda \varepsilon i \tau\left[\alpha \iota\right.$, "it is sold", or a form of $\pi 0 \lambda_{\imath} \tau \varepsilon v \dot{\omega} \omega$ in the meaning of "to be

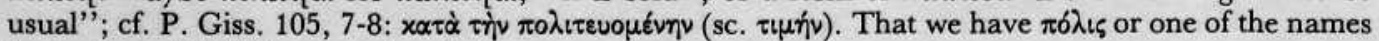
beginning with $\Pi \circ \lambda$ - seems less likely.

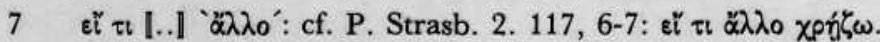

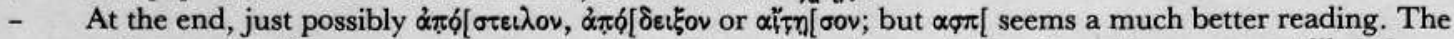
verb meaning "let me know", then, will have been in the lacuna in line 6 , and here we most likely have the dorák̆ouat-wish. 

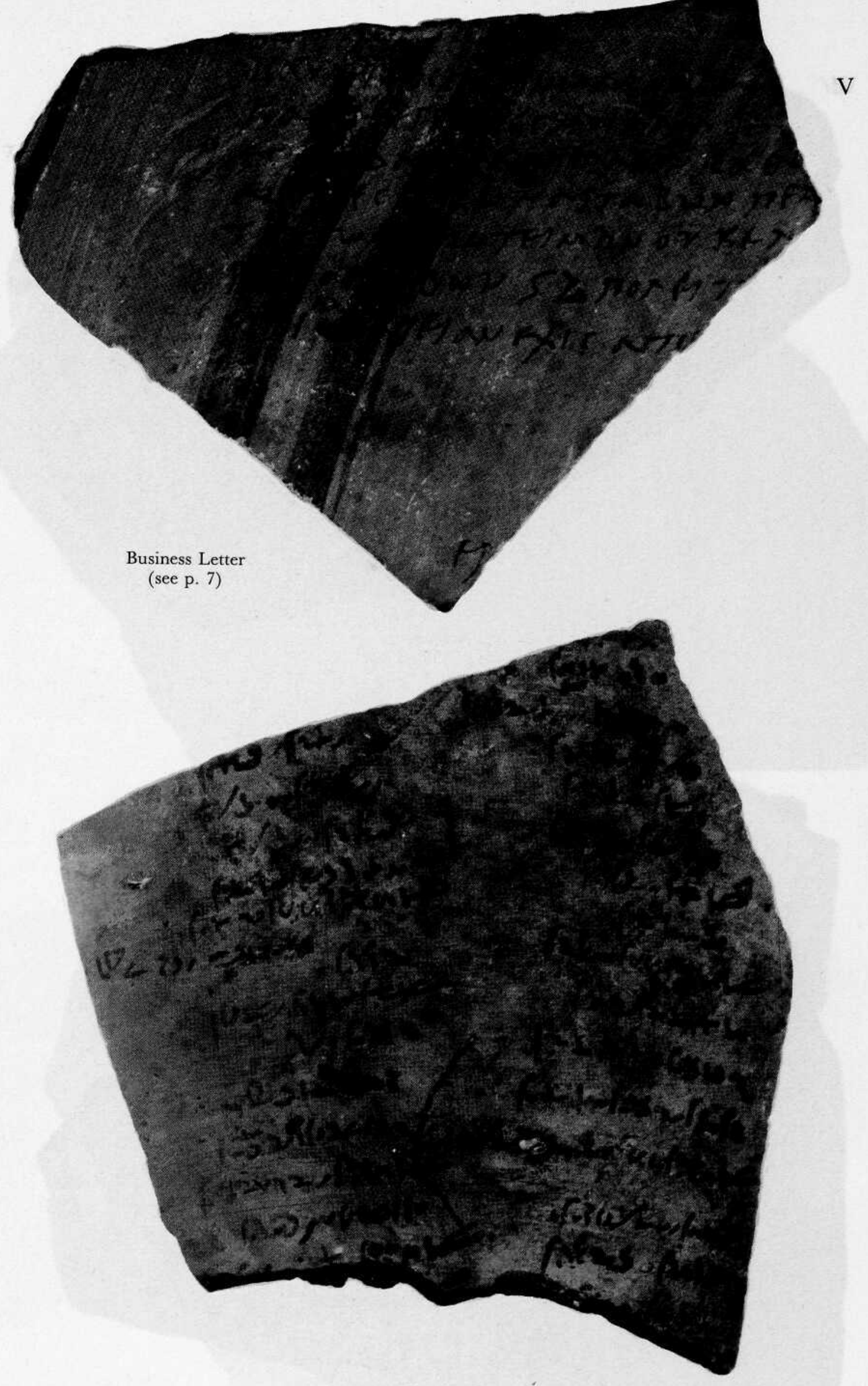

List of names

(see p. 151 no. 1) 